\title{
Bir İ̧letme Örneğinde Optimal Bitkisel Üretim Deseninin ve Uygun Ekipman Setinin Belirlenmesi
}

\author{
Bülent COSKUN²
}

Cengiz OZARSLAN ${ }^{2}$

\author{
Geliş Tarihi : 05.09.1999
}

\begin{abstract}
Özet: Bu çalışmada, Adnan Menderes Universitesi Ziraat Fakültesi çiftliğinin tarım yapılan alanları, kısıtlı sayıdaki tarım alet-makinaları ile traktör varlığı, çiftlik bünyesindekì işgücü ve diğer alt yapı yatırımları dikkate alınarak; ișletmenin gelirini en büyükleyecek üretim deseninin belirlenmesi ve bu üretim deseni için en uygun alet-makina setleri ile traktör sayısı ve işgücü gereksinimierinin belirlenmesi amaçlanmıștır.

Bu amaçla, mevcut Uretim planı dikkate alinarak, 3 farklı ekipman SET'i için doğrusal programiama modeli oluşturuimuș ve QSB programi ile olușturulan model çözülmüștür.

Sonuçta işletmenin mevcut üretim desenine alternatif olabilecek ve maksimum gelit getirebilecek ürün deseni, 154.2 ha buğday, 1.3 ha pamuk ve 2.97 ha II ürün misır olarak bulunmuștur. Traktör sayisi 80 BG'lük 4 adet traktör ve operatör; mevsimlik işçi sayısı ise 3 adet olarak bulunmuştur. Işletme geliri ise 65552.1 \$ olarak saptanmıştır
\end{abstract}

Anahtar Kelimeler: Doğrusal programiama, optimal bitkisel üretim deseni.

\section{Determination of Optimal Crop Pattern and Appropriate Equipment Set for a Model of Farm}

\begin{abstract}
: in this study, it has been aimed to determine the crop pattern which will maximize the incomes of the management and to delermine the most suitable equipment sets and number of tractors and man power necessity for this crop pattern taking into consideration to the less number of agricultural equipments, tractor existence, man power, the farming areas of Adnan Menderes University of Agricultural Faculty and the other investments.

With this aim, taking into consideration to the existing production plan, linear programming model has been constituted for 3 different equipment sets and the costituted model has been analyzed with QSB program.

As a result, the crop pattern which will bring maxsimum income and will be alternative to the existing crop pattern of the management has been found as 154.2 ha wheat, 1.3 ha cotton and 2.97 ha second crop corn. Number of tractors and seasonal worker has been found out 4 of $80 \mathrm{MP}$ tractor and operator and 3 number of seasonal workers. The management income has been established as $65552,1 \$$.
\end{abstract}

Key Words : Linear programing, optimum crop pattern.

Giris

Tarımın modernleşmesi mekanizasyonun üretime katılımını artırmaktadır. Mekanizasyon önemli bir maliyet girdisidir ve genel äretim içindeki payı mekanizasyon derecesinin artması ile artış göstermektedir. Bu nedenle tarımsal üretimden beklenen kazancin sağlanmasi için üretim planına uygun mekanizasyon kapasitelerinin seçimi veya kapasiteye uygun üretim planlarinin yapilması gerekir.

Çeşit olarak değişik ürünlerin üretildiği işletmelerde işlemierin çeşitliliği ve aynı zaman dilimine rastlanması gibi nedenler mekanizasyon planlaması sorununu karmaşık biçime dönüştürmekte ve çözüm için etkin sayısal optimizasyon tekniklerinin kuilanımını zorunlu kılmaktadır. Bu tekniklerden, sınırlı kaynakłarın ön görülen bir amacı gerçekleştirecek şekilde üretim așamasinda dağıIımını sağlayan doğrusal programlama tekniği (LP) ve buna ilişkin çözüm yöntemleri, özellikleri itibarıyla mekanizasyon planlaması problemlerinin çözümünde kullanılabilecek tekniklerin başında gelmektedir. L.P tekniği değişik işletme birimleri için işletme özelliklerine uygun biçimde yapılandirılarak farklı optimizasyon modelleri biçiminde düzenlenebilir.

Literatürlerde tarım ve tarımsal mekanizasyonda planlamaya ilişkin olarak çok sayıda LP modelleme örneklerine rastlanmaktadır. Örneg̈in; Audsley, tarla tarımı yapılan alanlarda işçilik-makina zamanları, işlem ve ürünlerin ardișımı, ürün deseni, alan, insan-makina sayıları gibi teknik ve ekonomik kısıtları karşılayan üretim planlamaları ùzerinde çalıșmalar yapmıştır(Audsiey, 1979 ve Audsley, 1983). Sakai ve arkadaşları, yeni üretime açılmış veya alet-makinasi olmayan işletmeler için optimum "insan işgücü-makina-bitki" sistemlerine ilişkin planlanmalarda LP tekniğinden yararlanmışlardır (Sakai ve ark. 1978). Evcim, tarımsal işletmelerde LP tekniğini kullanarak, mekanizasyon ve işçilik planlamalarının nasıl yapılacağı üzerine çalışmalar gerçekleştirmiştir (Evcim, 1986). Buna benzer uygulamalarin yurt içi ve yuirt dişi çok sayıda örneği mevcuttur. Etkin bir mekanizasyon planlamasi için amaca uygun makina seçiminin lyi yapılmasi, iyi bir işletmecilik anlayışına sahip olunması ve bașarılı bir işgúcù planlamasının yapılması zorunludur.

\footnotetext{
I Bu çalışma Adnan Men. Univ. Araştirma Fonu tarafından desteklenen ZRF 96016 nolu projeden yararlanılarak hazırlanmıştır.

${ }^{2}$ Adnan Menderes Univ. Ziraat Fak. Tarım Makinaları Bölümü-Aydın
} 


\section{Materyal va Yöntem}

\section{İsletme özellikıri ve ürün deseni}

Incelemeye alinan işletme Adnan Menderes Üniversitesi Ziraat Fakültesı ne bağlı Araştırma ve Üretim Çiftliği olup Aydın ili Koçari ilçesi Çakmar köyünde bulunmaktadır. Işletmenin büycìklüğü 2200 da olup, toplam işlenen alan 1556 da'dır. Işiotmede ağırikklı üretim kolu tarla bitkileri yetiştiriciliği olup, şok az alanda bahçe bitkileri üretimi ve kısıthı ölçüde de hayvancılik yapılmaktadir. Bahçe bitkileri ve ha,vancilık üretim kollarında henüz yüksek düzeyde gelir getirici üretim

Çizelge 1. Yetiştirilen ürünler ve ürün ardışımlanı.

\begin{tabular}{|l|l|c|}
\hline \multicolumn{1}{|c|}{ Önceki urün } & \multicolumn{1}{|c|}{ Ürün } & Üretim alar:I (ha) \\
\hline I.Ürün misır & Buğday & 96 \\
\hline II.Ürün misır & Pamuk & 28 \\
\hline Pamuk & 1.ürün mısır & 31,6 \\
\hline Buğday & II.Ürün misır & 96 \\
\hline
\end{tabular}

Çizelge 2. Pamuk için agroteknik işiem aşamaları.

\begin{tabular}{|c|c|c|c|}
\hline $\begin{array}{l}\text { Işlem } \\
\text { no }\end{array}$ & Işlem adt & $\begin{array}{l}\text { Kullanilan } \\
\text { ekipman }\end{array}$ & $\begin{array}{l}\text { Tah. Işlem } \\
\text { zamani } \\
\end{array}$ \\
\hline 1 & Set bozma & Tesviye küreği & 1-14 Kasim \\
\hline 2 & Sap parçalama & $\begin{array}{l}\text { Sap parçalama } \\
\text { makinas! }\end{array}$ & 1-14 Kasim \\
\hline 3 & Derin sürüm & Pulluk & 1-6 Nisan \\
\hline 4 & | kileme & $\begin{array}{l}\text { Diskli tirmik } \\
\text { (2 Kat) }\end{array}$ & 7-14 Nisan \\
\hline 5 & llaçlama & $\begin{array}{l}\text { Tarla } \\
\text { pülverizatörú }\end{array}$ & 7-14 Nisan \\
\hline 6 & Ücleme & Diskli tirmik & 7-14 Nisan \\
\hline 7 & Gübreleme & $\begin{array}{l}\text { Sant. gübre } \\
\text { dağitma mak. }\end{array}$ & 15-20 Nisan \\
\hline 8 & Kariştıma & Diskli tirmik & 15-20 Nisan \\
\hline$\overline{9}$ & Toprak bastirma & $\begin{array}{l}\text { Sürgü+merdane } \\
\text { ( } 2 \text { Kat) }\end{array}$ & 21-30 Nisan \\
\hline 10 & Ekim & $\begin{array}{l}\text { Universal ekim } \\
\text { makinasi }\end{array}$ & 1-6 Mayıs \\
\hline 11 & Sira arası çap. & $\begin{array}{l}\text { Frezeli ara capa } \\
\text { mak. }\end{array}$ & 21-30 Mayıs \\
\hline 12 & Sıra üzeri çap. & Elle & 21-30 Mayis \\
\hline 13 & \begin{tabular}{|l} 
Tekleme \\
\end{tabular} & Elle & 1-7 Haziran \\
\hline 14 & laçlama & $\begin{array}{l}\text { Tarla } \\
\text { pülverizatörü }\end{array}$ & 8-14 Haziran \\
\hline 15 & Ara çapalama & $\begin{array}{l}\text { Kazayakiı } \\
\text { kültivatör }\end{array}$ & 21-30 Haziran \\
\hline 16 & Ust gubreleme & $\begin{array}{l}\text { Sant.gübre } \\
\text { dağitma mak. }\end{array}$ & 21-30 Haziran \\
\hline 17 & Set yapma & $\begin{array}{l}\text { Selte makinas! } \\
(2 \mathrm{kez})\end{array}$ & 1-6 Temmuz \\
\hline 18 & 1.Sulama & Işçi & 1-6 Temmuz \\
\hline 19 & Ot aima & El çapasi & 15-20 Temmuz \\
\hline 20 & 2. Sulama & Işçi & 21-30 Temmuz \\
\hline 21 & 3. Sulama & Iş̧̧i & 15-20 Ağustos \\
\hline 22 & 4. Sulama & Işçi & 1-6 Eylai \\
\hline 23 & Hasat (1,El) & Iş̧i & 15 Eylül-6 Ekim \\
\hline 24 & Taşıma & Tarim arabasi: & 15 Eylul-6 Exim \\
\hline 25 & Hasat (2.EI) & Ișci & 21-30 Ekim \\
\hline 26 & Tașima & Tarim arabasi & 21-30 Ekim \\
\hline
\end{tabular}

yapılamamaktadır. Tarla ürünlerinden ağırlıklı olarak pamuk, mısır ve buğday üretimi gerçekleştirilmektedir. Ișletmenin gelirini bu ürünterden elde edilen gelirler olușturmaktadır. Bu ürünlerin yetiștirilmesinde uygulanan ürün ardışımları Çizelge 1 'deki gibidir.

\section{Agroteknik işlem aşamaları ve zamanları}

Işletmedeki üretim belirli zaman aralıklarına yayılmış mekanizasyon işlemleri ile gerçekleştirilmektedir. Bu işiem aşamalarının ürünlere, işlemlere, kullanilan ekipmanlara ve zamana göre dağılımlan Çizelge 2 'den Çizelge 5 'e kadar verilmiștir.

Çizelge 3. Buğday için agroteknik işlem aşamaları.

\begin{tabular}{|c|c|c|c|}
\hline $\begin{array}{l}\text { Işlem } \\
\text { No }\end{array}$ & Işlem ad! & $\begin{array}{l}\text { Kullanilan } \\
\text { ekipman }\end{array}$ & $\begin{array}{l}\text { Tah.işlem } \\
\text { zamanı }\end{array}$ \\
\hline 1 & Set bozma & Tesviye küreği & 21-30 Ekim \\
\hline 2 & Sap parçalama & $\begin{array}{l}\text { Sap parçalama } \\
\text { makinasi }\end{array}$ & 21-30 Ekim \\
\hline 3 & Derin süram & Pulluk & $1-6$ Kasım \\
\hline 4 & Ikileme & $\begin{array}{l}\text { Diskli tirmık } \\
\text { ( } 2 \text { kat) }\end{array}$ & 1-6 Kasım \\
\hline 5 & Gübreleme & $\begin{array}{l}\text { Sant gübre } \\
\text { dağıtma mak. }\end{array}$ & 7-14 Kasım \\
\hline 6 & Uçeme & Diskli tirmik & 7-14 Kasim \\
\hline 7 & Ekim & $\begin{array}{l}\text { Kombine ekim } \\
\text { makinası }\end{array}$ & 1-14 Aralik \\
\hline 8 & Tlaçlama & $\begin{array}{l}\text { Tarla } \\
\text { pălverizatorū }\end{array}$ & $21-30$ Ocak \\
\hline 9 & Gübreleme & $\begin{array}{l}\text { Sant.gabre } \\
\text { dağıtma mak. }\end{array}$ & $1-6$ Şubat \\
\hline 10 & Karıştırma & Diskli tırmık & 1-6 Subat \\
\hline 11 & Set yapma & Sette makinası & $21-30$ Nisan \\
\hline 12 & Sulama & Işçi & 21-30 Nisan \\
\hline 13 & Hasat & $\begin{array}{l}\text { Biçerdóver } \\
\text { (yüklenici) }\end{array}$ & 8-14 Haziran \\
\hline 14 & Tașıma & Tarim arabası & 8-14 Haziran \\
\hline 15 & Balyalama & $\begin{array}{l}\text { Balya mak. } \\
\text { (yoklenici) }\end{array}$ & 8-14 Haziran \\
\hline 16 & Baiya taşıma & Tarm arabası & 8-14 Haziran \\
\hline
\end{tabular}

Çizelge 4. L.Urün mısır için agroteknik işlem aşamaları .

\begin{tabular}{|c|c|c|c|}
\hline $\begin{array}{l}\text { șlem } \\
\text { no }\end{array}$ & Işiem adı & Kullanilan ekipman & $\begin{array}{l}\text { Tah:Işlem } \\
\text { zamani }\end{array}$ \\
\hline 1 & Set bozma & Tesviye küreği & 21-30 Ekim \\
\hline 2 & $\begin{array}{l}\text { Sap } \\
\text { parçalama }\end{array}$ & $\begin{array}{l}\text { Sap parçalama } \\
\text { makinası }\end{array}$ & 21-30 Ekim \\
\hline 3 & Derin sarüm & Pulluk & 1-6 Kasım \\
\hline 4 & Sürüm & Pulluk & 1-6 Nisan \\
\hline 5 & ikileme & $\begin{array}{l}\text { Diskli turmık } \\
\text { (2 Kat) }\end{array}$ & 7-14 Nisan \\
\hline 6 & ilaçlama & Tarla pülverizatơru & 7-14 Nisan \\
\hline 7 & Uçleme & Diskli tırmık & 7-14 Nisan \\
\hline 8 & Göbreleme & $\begin{array}{l}\text { Sant, gübre } \\
\text { dağıtma mak. }\end{array}$ & 15-20 Nisan \\
\hline 9 & Kariştirma & Diskli tirmık & 15-20 Nisan \\
\hline 10 & $\begin{array}{l}\text { Toprak } \\
\text { bastırma }\end{array}$ & $\begin{array}{l}\text { Sũrgü+merdane } \\
\text { ( } 2 \text { kat) }\end{array}$ & 21-30 Nisan \\
\hline
\end{tabular}


Çizeige 4. I.Urün misit için agroteknik ișlem așamaları (Devam)

\begin{tabular}{|c|c|c|c|}
\hline $\begin{array}{l}\text { Işlem } \\
\text { no }\end{array}$ & Işlem adı & Kullanilan ekipman & $\begin{array}{l}\text { Tah.işlem } \\
\text { zamanı }\end{array}$ \\
\hline 11 & Ekim & $\begin{array}{l}\text { Ũniversal ekim } \\
\text { makinası }\end{array}$ & 21-30 Nisan \\
\hline 12 & $\begin{array}{l}\text { Sira arası } \\
\text { çapalama }\end{array}$ & $\begin{array}{l}\text { Frezeli ara çapa } \\
\text { makinası }\end{array}$ & $15-20$ Mayis \\
\hline 13 & $\begin{array}{l}\text { Sira üzeri } \\
\text { çapalama }\end{array}$ & Elle & 15-20 Mayıs \\
\hline 14 & Tekleme & Elle & 21-30 Mayis \\
\hline 15 & $\begin{array}{l}\text { Ara } \\
\text { çapalama }\end{array}$ & $\begin{array}{l}\text { Kazayaklı } \\
\text { kültivatör }\end{array}$ & 8-20 Haziran \\
\hline 16 & $\begin{array}{l}\text { Üst } \\
\text { gübreleme }\end{array}$ & $\begin{array}{l}\text { Sant.gủbre } \\
\text { daĝitma mak. }\end{array}$ & 1-6 Temmuz \\
\hline 17 & Set yapma & $\begin{array}{l}\text { Sette makinasi } \\
(2 \mathrm{kez})\end{array}$ & 6-14 Temmuz \\
\hline 18 & 1.Sulama & Tșçi & 6-14 Temmuz \\
\hline 19 & 2. Sulama & Tşçi & $\begin{array}{l}21-30 \\
\text { Temmuz }\end{array}$ \\
\hline 20 & 3. Sulama & Tş̧̧i & 7-14 Ağustos \\
\hline 21 & 4. Sulama & Tșçi & 1-6 Eylul \\
\hline 22 & Hasat & Biçerdöver (misif) & 15-20 Ekim \\
\hline 23 & Taşıma & Tarim arabasi & 15-20 Ekim \\
\hline
\end{tabular}

Çizelge 5. II. Urün mısır için agroteknik işlem aşamaları .

\begin{tabular}{|c|c|c|c|}
\hline $\begin{array}{l}\text { Tşlem } \\
\text { no }\end{array}$ & Isiem adi & $\begin{array}{l}\begin{array}{l}\text { Kullanilan } \\
\text { ekipman }\end{array} \\
\end{array}$ & \begin{tabular}{|l|} 
Tah.işlem \\
zamanı \\
\end{tabular} \\
\hline 1 & Aniz bozma & Pulluk & 15-20 Haziran \\
\hline 2 & Set yapma & $\begin{array}{l}\text { Sette makinasi } \\
(2 \mathrm{kez})\end{array}$ & 15-20 Haziran \\
\hline 3 & Sulama & Iş̧̧i & 15-20 Haziran \\
\hline 4 & Set bozma & Tesviye küreği & 21-30 Haziran \\
\hline 5 & Derin sürūm & Pullok & 21-30 Haziran \\
\hline 6 & Íkileme & $\begin{array}{l}\text { Diskli turmik } \\
\text { (2 kat) }\end{array}$ & 21-30 Haziran \\
\hline 7 & Gübreleme & $\begin{array}{l}\text { Sant.gübre } \\
\text { dağıma mak. }\end{array}$ & 21-30 Haziran \\
\hline 8 & Karișlırma & Diskli tırmık & 21-30 Haziran \\
\hline 9 & Toprak bastirma & $\begin{array}{l}\text { Sürgô+merdane } \\
\text { (2 kat) }\end{array}$ & 21-30 Haziran \\
\hline 10 & Ekim & $\begin{array}{l}\text { Universal ekim } \\
\text { makinası }\end{array}$ & 21-30 Haziran \\
\hline 11 & Sira Arasi Cap. & $\begin{array}{l}\text { Frezeli ara çapa } \\
\text { mak. }\end{array}$ & 7-14 Temmuz \\
\hline 12 & Sira úzeri çap. & Elle & 7-14 Temmuz \\
\hline 13 & Tekleme & Elle & 7-14 Temmuz \\
\hline 14 & Ara çapalama & $\begin{array}{l}\text { Kazayakli } \\
\text { kültivatör }\end{array}$ & 7-14 Temmuz \\
\hline 15 & Ust gübreieme & $\begin{array}{l}\text { Sant.gübre } \\
\text { dağıtma mak. }\end{array}$ & 7-14 Temmuz \\
\hline 16 & Karıștirma & Diskli turmik & 7-14 Temmuz \\
\hline 17 & Set yapma & $\begin{array}{l}\text { Sette makinas! } \\
\text { ( } 2 \mathrm{Kez})\end{array}$ & 7-14 Temmuz \\
\hline 18 & 1. Sulama & |ş̧̧i & $\begin{array}{l}15-20 \\
\text { Temmuz }\end{array}$ \\
\hline 19 & Tlaçlama & $\begin{array}{l}\text { Tarla } \\
\text { pülverizatöro }\end{array}$ & 1-6 Ağustos \\
\hline 20 & 2. Sulama & Işçi & 1-6 Aǵustos \\
\hline 21 & 3. Sulama & Iş̧̨i & 15-20 Ag̈ustos \\
\hline 22 & 4. Sulama & Ișçi & 1-6 Eylal \\
\hline 23 & 5. Sulama & |ş̧⿻i & 15-20 Eylü \\
\hline 24 & Yabanci of müc. & Elle & 15-20 Eylül \\
\hline 25 & Hasat & $\begin{array}{l}\text { Biçerdóver } \\
\text { (Misir) }\end{array}$ & $7-20$ Kasim \\
\hline 26 & Taşıma & Tanim arabasi & 7.20 Kasim \\
\hline
\end{tabular}

\section{Traktör ve alet́ makíne setleri}

Tarımsal ișlemlerin çoğunluğu ișletmede bulunan ekipmanlarla gerçekleştirilmektedir. Ancak, buğday ve misır hasadi ile sap balyalama işlemi yükleniciye yaptırılmaktadır. Pamuk hasadı ile bazi hassas çapalama işiemleri ve sulama el işçiliği ile yapılmaktadır. Bu durum göz önüne alınarak, işletmede bulundurulmasi gereken alet-makinalar ile traktör güç grupları 3 farklı set biçiminde Çizelge 6'da verilmiştir. Setlerde yer alan traktörler ve ekipmanların bir kısmi işletmede mevcut olup, bir kısmı ise alınması ön görümü ile setlere ilave edilmiștir. I.SET'te yer alan traktör Ford 3600, II. SET'te yer alan traktör FIAT 70-56 ve III. SET'te yer alan traktör FIAT 80-66 marka traktördür.

\section{Çalışılabilir zamanlar}

Tarımsal uygulamalarda işlem zamanlarımın doğru belirlenmesi başarılı bir üretim için önemlidir. Modelleme çalışmalarında işlem zamanlarına tahmini olarak yer verilir. Tahmine dayait olan bu verinin belirlenmesi için. yıl periyodu içindeki toplam çalişma günủ ve bu günlerdeki çalışılabilir gün olastlıklarının bilinmesi gerekir. Toplam çalışma günü, resmi tatiller, hastalik vb. gibi zorunlu izinler düşüldükten sonra yılın değişik aylarında incelenen periyotlar için belirlenebilir. Çalışılabilir gün olasılığı ise bölgeye düșen yağıș miktarı, toprağın geçirgenlik özelliği, eğimi, hava koșulları vb. değerler kullanilarak ortaya konulabilir.

Çizelge 6. Traktor ve alet-makina setleri

\begin{tabular}{|c|c|c|c|}
\hline Set & I & II & III \\
\hline Traktör motor gücü $(\mathrm{kW})$ & 34,8 & 51.5 & 58,8 \\
\hline Traktör sayısı (adet) & \multicolumn{3}{|l|}{$1 \ldots 10$} \\
\hline Alet-makina & \multicolumn{3}{|c|}{ Ozelliği } \\
\hline $\begin{array}{l}\text { Ara çapa aleti } \\
\text { (kazayakil kultivatör) }\end{array}$ & $\begin{array}{l}175 \mathrm{~cm} \\
\left(7^{7}(i)\right)\end{array}$ & $\begin{array}{l}218 \mathrm{~cm} \\
(9 \%) \\
\end{array}$ & $275 \mathrm{~cm}(111 \mathrm{i})$ \\
\hline $\begin{array}{l}\text { Diskli turmik } \\
\text { (asilir, tandem) }\end{array}$ & $\begin{array}{l}222 \mathrm{~cm} \\
24 \text { siralı }\end{array}$ & \begin{tabular}{|l|}
$254 \mathrm{~cm}$ \\
28 sirali \\
\end{tabular} & \begin{tabular}{|l|}
$254 \mathrm{~cm}$ \\
28 siralı
\end{tabular} \\
\hline Frezeli ara çapa mak. & $\begin{array}{l}210 \mathrm{~cm} \\
3 \text { sirail } \\
\end{array}$ & $\begin{array}{l}350 \mathrm{~cm} \\
5 \text { sirali }\end{array}$ & $\begin{array}{l}350 \mathrm{~cm} \\
5 \text { sirali } \\
\end{array}$ \\
\hline Kom tahil ekim mak. & \begin{tabular}{|l|}
$204 \mathrm{~cm}$ \\
17 ayakll \\
\end{tabular} & $\begin{array}{l}228 \mathrm{~cm} \\
19 \text { ayakil } \\
\end{array}$ & \begin{tabular}{|l|}
$264 \mathrm{~cm}$ \\
22 ayakls \\
\end{tabular} \\
\hline Kulaklt pulluk & $\begin{array}{l}60 \mathrm{~cm} \\
2 \text { gövdeli }\end{array}$ & \begin{tabular}{|l|}
$90 \mathrm{~cm}$ \\
3 gövdeli \\
\end{tabular} & $\begin{array}{l}120 \mathrm{~cm} \\
4 \text { gövdeli }\end{array}$ \\
\hline Sant güb. daǵ Mak, & $\begin{array}{l}1200 \mathrm{~cm} \\
\text { Tek diskli }\end{array}$ & \begin{tabular}{|l|}
$1200 \mathrm{~cm}$ \\
Tek diskli \\
\end{tabular} & $\begin{array}{l}2000 \mathrm{~cm} \\
\text { cift dikli }\end{array}$ \\
\hline Sap parçalama mak. & $220 \mathrm{~cm}$ & $220 \mathrm{~cm}$ & $220 \mathrm{~cm}$ \\
\hline $\begin{array}{l}\text { Sette makinası } \\
\text { (tek ünite, } 8 \text { kovali) }\end{array}$ & $1000 \mathrm{~cm}$ & $1000 \mathrm{~cm}$ & $1000 \mathrm{~cm}$ \\
\hline Surgü+merdane & $300 \mathrm{~cm}$ & $300 \mathrm{~cm}$ & $300 \mathrm{~cm}$ \\
\hline $\begin{array}{l}\text { Tar. Arabası (tek dingilli } \\
\text { devirmeli sac kasa) }\end{array}$ & 3 ton & 4 ton & 6 ton \\
\hline Tarla pülverizatơrú & $\begin{array}{l}700 \mathrm{~cm} \\
400 \mathrm{it} \\
\end{array}$ & \begin{tabular}{|l|}
$700 \mathrm{~cm}$ \\
$400 \mathrm{It}$ \\
\end{tabular} & \begin{tabular}{|l|}
$900 \mathrm{~cm}$ \\
$800 \mathrm{it}$
\end{tabular} \\
\hline Tesviye küreği & $200 \mathrm{~cm}$ & $200 \mathrm{~cm}$ & $200 \mathrm{~cm}$ \\
\hline Univ ekim makinası & $\begin{array}{l}260 \mathrm{~cm} \\
4 \text { siralı } \\
\end{array}$ & $\begin{array}{l}260 \mathrm{~cm} \\
4 \text { sirali }\end{array}$ & $\begin{array}{l}260 \mathrm{~cm} \\
4 \text { sirail } \\
\end{array}$ \\
\hline
\end{tabular}


Incelenen ișletmenin bulunduğu Aydın ili koşullarında toplam çalışma günü değeri, çalışılabilir gün olasılığı ve tarımsal ișlemlerin yoğunlaștığı periyotlar dikkate alınarak 1 yıl 8 periyoda bölünmüș ve bu periyotlardaki çalışılabilir zamanlar Çizelge 7'deki gibi ortaya konulmuştur.

\section{Planlamada kullanılan çözümleme yöntemi}

Araştırma ve uygulama çiftliği bünyesindeki üretim planlaması Sakai ve arkadaşlarının ortaya koyduğu yöntemden yararlanilarak ortaya konan modele göre yapılmıştır ( Sakai ve ark.,1978). Bu modelin ana yapısı Şekil 1'deki akıș diyagramında verilmiștir. Bu modelleme ile hem mekanizasyon maliyetleri dikkate alınarak ve hem de mekanizasyon maliyetieri dikkate alınmadan optimizasyon işlemi gerçekleştirilebilmektedir. Model 8 aşamalt bir çözümủ içermektedir.

Çizelge 7. Çalışılabilir gün olasılığı ve zamanı.

\begin{tabular}{|l|l|l|l|l|}
\hline No & \multicolumn{1}{|c|}{ Periyot } & $\begin{array}{l}\text { Toplam } \\
\text { çalışma } \\
\text { zamanı(h) }\end{array}$ & $\begin{array}{l}\text { Çalışılabi- } \\
\text { lir gün } \\
\text { olasıllı̆ı }\end{array}$ & $\begin{array}{l}\text { Çalişılabi- } \\
\text { lir zaman } \\
(\mathrm{h})\end{array}$ \\
\hline 1 & 1 Aralık-30 Mart & 795.35 & 0.366 & 291.69 \\
\hline 2 & 1 Nisan-30 Nisan & 200.15 & 0.558 & 111.09 \\
\hline 3 & 1 Mayıs-7 Haziran & 258.37 & 0.852 & 220.13 \\
\hline 4 & 8 Haziran-30 Haziran & 162.07 & 1 & 162.07 \\
\hline 5 & 1 Tem.-30Temmuz & 208.55 & 1 & 208.55 \\
\hline 6 & 1 Ağustos-30 Ağustos & 216.1 & 1 & 216.1 \\
\hline 7 & 1 Eylül-7 Ekim & 259.45 & 0.99 & 256.85 \\
\hline 8 & 8 Ekim-30 Kasım & 355.22 & 0.9 & 319.69 \\
\hline
\end{tabular}

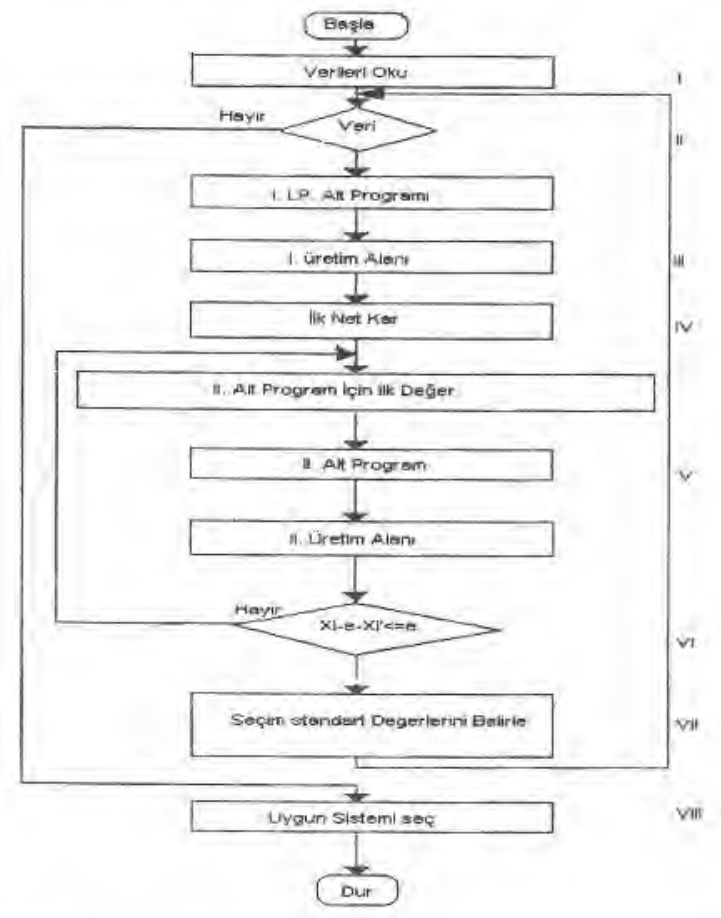

Şekil 1. Model akış diyagramı.

\section{I. aşama:}

Modelin ilk aşaması veri giriş aşamasıdır, $\mathrm{Bu}$ aşamada $A, A_{i}, i, j, D_{j}, Q_{j}, R_{j}, q_{j i}, r_{j i}, P_{i}{ }^{\prime}$ ve $F_{c j} j^{\prime}$ değerlerinin işletme koşullarına göre belirlenerek veri tabanının oluşturulması gerekir (EK: 1 semboller).

Bu değerlerden.

$Q_{j}=D_{j} \cdot K_{1}$

$R_{j}=D_{j}, K_{2}$

bağintısıyla hesaplanmakta olup $\mathrm{K}_{1}$ ve $\mathrm{K}_{2}$ değerleri ilk așamada karar değişkeni olarak modelde yer almakta, daha sonra model girdisi olmaktadir.

q değerleri alet-makine için zaman gereksinimleri olup,

$$
q=\frac{10}{v \cdot w \cdot e}
$$

bağıntısi ile hesaplanır (Evcim,1990). Özellik gösteren tașıma işi için zaman gereksinimi ${ }_{i}$

$$
q_{t}=\frac{Y_{i} \cdot D}{v \cdot T}+\frac{(U+L) \cdot Y_{i}}{T}
$$

bağıntısıyla hesaplanır (Özbaydur, 1996). A, A,$i$ ve j ile makine setlerine göre hesaplanan $q$ ve $q$ t değerleri ve yetiştirilen ürünlerin işlem așamalarına göre düzenlenen $q_{i j}$ deg̉erleri, elle yapilan ișlemler için insan işgüicü gereksinimi (Anonim,1994,1998-a), her ürün ve periyot için düzenlenen insan işgücü gereksinimi ( $r_{i j}$ ) verileri ZRF-96016 nolu araștırma raporundan alınmıştır. (Coşkun ve ark., 1999).

Ürünlerin öngörülen yetiştirme alanları dikkate alınarak, hasat sonu ürünlerden elde edilen gelir ile giderler arasındaki fark $P_{i}$ yi vermektedir.

$$
\begin{array}{ll}
P_{i}=T R_{i}-T C_{i} & 5 \\
T R_{i}=Y_{i} \cdot U P_{i} & 6 \\
T C_{i}=M t_{i}+M g a_{j}+M i i_{i}+Z C_{i}+F C_{i}+B C_{i}+M m_{i} & 7 \\
B C_{i}=M y a k_{i}+M y a g_{i}+M i s ̧ i & 8 \\
Z C_{j}=M M_{j}+M y u ̈ k_{i} & 9 \\
P_{i}^{\prime}=P_{j}+F_{i} & 10
\end{array}
$$

bağıntıları kullanılarak $\mathrm{Pi}_{i}$ hesaplanır. Bağıntılarda yer alan parametrelerin hesaplanmasında şu işlem adımları izlenir.

\section{Makina sabit maliyeti $\left(F C_{i}\right)$}

Makine sabit maliyetinin hesaplanması için alet makinaların yıllık kullanım sürelerinin bilinmesi gerekir. Yıllık kullanım süresi işletme özelliklerine göre,

$$
\begin{aligned}
& T_{i k}=q_{i k} \cdot A_{k i} \cdot g \\
& \text { bağıntısı ile hesaplanır. }
\end{aligned}
$$

Traktörler için yillık kullanım süreleri toplam ekipman kullanım süresinden hareket edilerek belirlenebilir.

Yillik ekipman kullanım süresi, ekipmanların ekonomik ömürleri, amortisman süreleri ve edinme maliyetlerinden yararlanılarak ve borçlanma faizi, yatırım 
faizi ve enflasyon oranı dikkate alınmak koșulu ile herbir SET için yıllık sabit kullanım giderleri COST adlı bilgisayar programı kullanılarak elde edilmiştir.

Ürünlerin yetiştirilme alanları dikkate alınarak herbir alet-makina SET'i için ürünler bazında elde edilen $\mathrm{FC}^{\prime} \mathrm{i}$ derlenerek, $\mathrm{FC}_{\mathrm{i}}$ deḡerleri

$$
F C_{1}=\frac{F C_{i}^{\prime} \cdot \Sigma q_{i t}}{\Sigma T_{1 k}+\Sigma T_{2 k}+\Sigma T_{3 k}+\Sigma T_{4 k}}
$$

eșitliğine göre hesaplanır. Eşitlikte.

$$
\begin{aligned}
& \Sigma q_{i t}=\Sigma q_{i k} \cdot g \\
& \Sigma T_{i k}=\Sigma q_{i t} \cdot A_{i k} \\
& \text { dir. }
\end{aligned} \quad(k=1 . . m)
$$

\section{Makina değişken maliyeti $\left(B C_{i}\right)$}

Değişken makine maliyetleri ürünler bazında yakıt, yağ ve operatör maliyetlerinin toplamından oluşturmaktadır.

$$
\mathrm{BC}_{\mathrm{i}}=\mathrm{Myak}_{\mathrm{i}}+\mathrm{Myag̃}_{i}+\mathrm{Mişi}
$$

\section{Yakıt maliyeti (Myaki)}

Tarımsal üretiminde önemli maliyet öğelerinden biri yakıt maliyetidir. Yakıt maliyeti, traktör-ekipman yüklenmesinden büyük oranda etkilenmek-tedir. Üretimde kullanılan alet-makina güç gereksinimi ve kullanım sıklığına bağlı olarak bu girdi değişiklik gösterir. Yakıt maliyetinin hesaplanması için üretim aşamalarında kullanılan ekipmanların, yakıt tüketim-lerinin bilinmesi gerekir. Diesel motora sahip bir traktörle kullanılan ekipmanlar için yakıt tüketim değeri;

$$
Y a k=Y \text {.EKMG }
$$

ile hesaplanmakta olup, burada $Y$ değeri;

$$
Y=2.64 . X+3.91-0.2 \sqrt{738 \cdot X+173}
$$

ile bulunur (Evcim,1990), $X$ ise

$$
x=\frac{E K M G}{M K M G}
$$

eşitliği ile hesaplanır.

Traktörler için eşdeğer kuyruk mili gücü (EKMG) ve maksimum kuyruk mili gücü (MKMG), motor gücüne ve çeki gücüne bağlı olarak ortaya konmakta olup, kuyruk mili gücünün 0.88 katı kullanılan ekipmanların çeki gücüne eşit alınarak, eşdeğer kuyruk mili gücô bulunabilir. Buna göre,

$$
E K M G=\frac{C ̧ G}{0.88}
$$

bağıntısıyla hesaplanır.

Maksimum kuyruk mili gücü ise motor gücünün 0.87 katı değerine eşittir (Evcim,1990).
MKMG $=0.87 . \mathrm{N}$

eşitliği ile hesaplanır.

3 farklı traktör güç grubu için eşitlik (20) yardımıyla hesaplanan maksimum kuyruk mili gücü (MKMG) değerleri Çizelge 8'de verilmiştir. Alan başına yakit maliyetleri ise,

Myaki $=q_{i j}$. Yak.F

bağıntısı ile hesaplanır.

\section{Yağ maliyeti (Myağj)}

Çalışmada yer alan Diesel motora sahip traktörlerin yağ tüketim değerleri (It/h) olarak, EKMG'ne bağlı olarak,

Yağ $=0.00059 . E K M G+0.02169$ 22

bağıntısıyla hesaplanabilir (Evcim, 1990).

Alan başına yağ inaliyetleri ise.

Myaği $=q_{i j}$. Yağ. $F Y$

bağıntisı ile hesaplanır.

\section{Operatör maliyeti (Mişi)}

Bu maliyet traktör sürücüsünün maliyetini kapsamaktadır. $1.5 \mathrm{\$} / \mathrm{h}$ olan bu maliyet alan birimine dönüştürülerek hesaplamalarda kullanılmıştır.

Tohum maliyeti (Mtohi)

Mtohi $) \mathrm{T}_{\mathrm{t}} \cdot \mathrm{F}_{\mathrm{t}}$

ile hesaplanir.

İlaç maliyeti (Mili)

Mili $=\mathrm{T}_{\mathrm{il}} . \mathrm{F}_{\mathrm{il}}$

ile hesaplanır.

Gübre maliyeti (Mgüi)

Mgüj $=\mathrm{T}_{\mathrm{g}} \cdot \mathrm{F}_{\mathrm{g}}$

ile hesaplanir.

\section{Mevsimlik işçi maliyeti $\left(\mathrm{Mm}_{\mathrm{i}}\right)$}

Agroteknik işlemlerde gereksinim duyulan çapalama, tekleme, sulama, elle hasat işlemlerindeki işçilik maliyetleri şöyle hesaplanır.

$$
\mathrm{Mm}_{\mathrm{i}}=\mathrm{C}_{\mathrm{h}} \cdot \mathrm{rij}_{\mathrm{ij}}
$$

\section{Diğer maliyetler $\left(Z c_{i}\right)$}

Sulama ve yüklenici giderlerinden oluşan maliyet,

$\mathrm{ZC}_{\mathrm{i}}=\mathrm{Msu}_{\mathrm{i}}+\mathrm{Myü}_{\mathrm{i}}$ $\mathrm{Msui}_{\mathrm{i}}=\mathrm{n}_{\mathrm{S}}, \mathrm{F}_{\mathrm{su}}$

bağıntılarıyla hesaplanır.

Üretimdeki giderler ve ürün gelirlerine göre hesaplanan $\mathrm{P}_{\mathrm{i}}$ ve $\mathrm{P}_{\mathrm{i}}$ 'değerleri $(5)$ ve (10) bağıntıları

Çizelge 8. SET'lerde kullanilan değişik traktör güçleri için hesaplanan MKMG değerleri.

\begin{tabular}{|l|l|l|l|}
\hline \multirow{2}{*}{ Güc grubu } & \multicolumn{1}{|l|}{ Motor } & \multicolumn{1}{|l|}{ Gücü } & MKMG \\
\cline { 2 - 4 } & $\mathrm{BG}$ & $\mathrm{kW}$ & $\mathrm{kW}$ \\
\hline $50 \mathrm{BG}$ & 47.28 & 34.8 & 30.276 \\
\hline $70 \mathrm{BG}$ & 69.97 & 51.5 & 44.81 \\
\hline $80 \mathrm{BG}$ & 79.89 & 58.8 & 51.156 \\
\hline
\end{tabular}


kullanılarak hesaplanmış ve bulunan değerler Çizelge 9 'da verilmiştir.

\section{Aşama}

Modelin ikinci aşaması amaç fonksiyonu ve kısıt denklemlerinin oluşturulması aşamasıdır. Bu aşamada Şekil 1'deki model için denklem sistemi aşağıdaki kalıba uygun olarak oluşturulmuştur .

Amaç fonksiyonu

$C_{\text {max }}^{\prime}=P_{1}^{\prime} \cdot X_{1}^{\prime}+P_{2}^{\prime} \cdot X_{2}^{\prime}+\ldots+P_{n^{\prime}}^{\prime}, X_{n^{\prime}}^{\prime}=P^{\prime} \cdot X^{\prime}$

Kısıt denklemleri

$\mathrm{X}_{1}{ }^{\prime}+\mathrm{X}_{2}{ }^{\prime}+\ldots . ., \mathrm{X}_{\mathrm{n}}{ }^{\prime}<=\mathrm{A}$

$q_{11} \cdot X_{1}^{\prime}+q_{12} \cdot X_{2}^{\prime}+\ldots \ldots+q_{1 n} \cdot X_{n}^{\prime}<=Q_{1}$

$q_{m 1} \cdot X_{1}{ }^{\prime}+q_{m 2} \cdot X_{2}+\ldots \ldots+q_{m n} \cdot x_{n}<=Q_{m}$

$r_{11} \cdot X_{1}^{\prime}+r_{12} \cdot X_{2}{ }^{\prime}+\ldots . .+r_{1 n} \cdot X_{n}{ }^{\prime}<=R_{1}$

$r_{m 1} \cdot X_{1}{ }^{\prime}+r_{m 2} \cdot X_{2}+\ldots \ldots+r_{m n} \cdot X_{n}<=R_{m}$

$X_{1}{ }^{\prime}>=0, X_{2}^{\prime}>=0 \ldots . X^{\prime}>=0$

Bu kalıplar dikkate alınarak; SET I,SET II ve SET III için denklem kalıpları oluşturulmuştur. SET I için örnek bir denklem kalıbı EK'te verilmiştir.

\section{Aşama}

Model ilk olarak mekanizasyon maliyetleri dahil edilmeden çözülür ve $X_{i}$ 'değerleri bulunur.

\section{Aşama}

Ilk toplam net gelir değeri;

$$
\mathrm{PT}^{\prime}=\mathrm{C}^{\prime}-\frac{\sum \mathrm{FC}_{\mathrm{i}}^{\prime}}{\mathrm{n}}
$$

eşitliğinden hesaplanır.

\section{Aşama}

Çözüm ile bulunan $X_{i}$ değerleri ve buna bağlı olarak yeniden hesaplanan $\mathrm{FC}_{j}$ 'ne göre,

Çizelge 9. $P_{i}$ ve $P_{i}$ 'değerleri.

\begin{tabular}{|l|l|l|l|l|l|l|}
\hline \multirow{2}{*}{ Üün } & \multicolumn{2}{|c|}{ SET I } & \multicolumn{2}{c|}{ SET II } & \multicolumn{2}{c|}{ SET III } \\
\cline { 2 - 7 } & $\begin{array}{l}\mathrm{Pi} \\
\$ / \mathrm{ha}\end{array}$ & $\begin{array}{l}\mathrm{Pi} \\
\$ / \mathrm{ha}\end{array}$ & $\begin{array}{l}\mathrm{Pi} \\
\$ / \mathrm{ha}\end{array}$ & $\begin{array}{l}\mathrm{Pi} \\
\$ / \mathrm{ha}\end{array}$ & $\begin{array}{l}\mathrm{Pi} \\
\mathbf{\$} / \mathrm{ha}\end{array}$ & $\begin{array}{l}\mathrm{Pi} \\
\$ / \mathrm{ha}\end{array}$ \\
\hline Pamuk & 733,5 & 785,0 & 972,4 & 1030,8 & 979,8 & 1038 \\
\hline Mısır I & 530,5 & 594,2 & 518,8 & 589,4 & 541,6 & 609,1 \\
\hline Mısır II & 410,4 & 471,2 & 399,9 & 468,7 & 418,1 & 482,5 \\
\hline Buğday & 743,4 & 789,5 & 735,0 & 787,1 & 745,7 & 795,6 \\
\hline
\end{tabular}

$$
F C_{i}=\frac{F C_{i}^{\prime} q_{i t}}{q_{1 t} \cdot x_{1}^{\prime}+q_{2 t} \cdot x_{2}^{\prime}+\ldots+q_{n t} \cdot x_{n}^{\prime}}
$$

bağıntısı ile $\mathrm{FC}_{\dot{j}}$ bulunur.

$F C_{j}$ ve $P_{i}$ ne bağlı olarak,

$\mathrm{P}_{\mathrm{i}}=\mathrm{P}_{\mathrm{i}}{ }^{\prime}-\mathrm{FC}_{\mathrm{i}}$

eşitliğinden $\mathrm{P}_{\mathrm{i}}$ hesaplanarak amaç fonksiyonu; $C_{\max }=P_{1} \cdot X_{1}+P_{2} \cdot X_{2}+\ldots+P_{n} \cdot X_{n}=P_{i} \cdot X_{1}$ 36

ve kısıt denklemleri,

$\mathrm{X}_{1}+\mathrm{X}_{2}+\ldots . . \mathrm{X}_{\mathrm{n}}<=\mathrm{A}$

$q_{11} \cdot X_{1}+q_{12} \cdot X_{2}+\ldots \ldots+q_{1 n} \cdot X_{n}<=Q_{1}$

$q_{m 1} \cdot X_{1}+q_{m 2} \cdot X_{2}+\ldots \ldots+q_{m n}, X_{n}<=Q_{m}$

$r_{11} \cdot X_{1}+r_{12} \cdot X_{2}+\ldots \ldots+r_{1 n} \cdot X_{n}<=R_{1}$

$r_{m 1} \cdot X_{1}+r_{m 2} \cdot X_{2}+\ldots \ldots+r_{m n} \cdot X_{n}<=R_{m}$

$X_{1}>=0, X_{2}>=0 \ldots X_{1}^{\prime}>=0$

biçiminde düzenlenir. Yeni $\mathrm{X}_{\mathrm{i}}=\mathrm{S}_{\mathrm{i}}$ değerleri bulunur. Yeni üretim alanları için net gelir

$\mathrm{PT}=\mathrm{C}_{\max }$

olarak hesaplanır.

\section{Aşama}

$\mathrm{X}_{\mathrm{i}}-\mathrm{e}-\mathrm{X}_{\mathrm{i}}<=\mathrm{e}$

koşulu sağlanıncaya kadar $V$, aşamadaki çözüme devam edilir.

\section{Aşama}

Sistem seçim kriterlerinin belirlendiği bu aşamada, model sonucuna göre herbir üründen elde edilen net gelir $\mathrm{P}_{\mathrm{i}} \mathrm{S}_{\mathrm{i}}$ bağıntısı ile belirlenerek, seçilen sistemin toplam geliri;

$$
\text { PT }=\sum_{\mid=1}^{n} P_{l} \cdot S_{l}
$$

bağınıısı ile belirlenir. Sistemin toplam iş gücü gereksinimi LT ye bağlı olarak, işgücü birimine düşen net gelir;

$$
P L=\frac{P T}{L T}
$$

bağıntısı ile bulunur. Eşitlikteki,

$$
L T=\sum_{I=1}^{n} \sum_{J=1}^{m} r_{j i} \cdot S_{i}
$$

dir. Periyot bașına iş gücü gereksiniminin standart sapması; 
$\sigma=\sqrt{\frac{\sum_{j=1}^{m}\left(\sum_{i=1}^{n} r_{j i} S_{i}\right)^{2}}{m}-\left(\frac{\sum^{m} \sum_{1 i=1}^{m} r_{j i} S_{i}}{m}\right)^{2}} 45$

bağıntısıyla bulunur.

\section{Aşama}

En uygun sistem seçim aşaması olan bu așamada en büyük $P_{T}$ ve $P_{L}$ değerleri ile en küçúk $\sigma$ değerine sahip olan sistem, optimum sistem olarak seçilir.

\section{Bulgular ve Tartişma}

Incelenen işletmede mevcut uygulanan urün deseni baz alınarak yapilan çözümlemede, ilk așamada traktör ve operatör ile mevsimlik işçi sayısı karar değişkeni olarak alınmıştır. Daha sonra bulunan değerler tam sayıya dönüştürülerek model girdisi olarak kullanıımıştir. Bulunan traktör ve mevsimlilk işçi sayıları dikkate alınarak makina sabit maliyeti dahil ve dahil edilmeden model iki alternatifli olarak çözuìmüş ve aşağıdaki sonuçlar bulunmuştur.

SET | için elde edilen sonuçlar Çizelge 10'da verilmiştir. Sonuçlar makina sabit maliyetlerinin hesaplamalara dahil edildiği alternatifleri içermektedir. Bu koşulda en yüksek gelir 6 traktör ve 3 mevsimlik işçiye sahip olma alternatifinde $49326,5 \$$ olarak gerçekleşmektedir. SET II ve SET III için bu değerler Çizelge 11 ve 12 'de verilmiştir. SET II için 5 traktör ve 3 mevsimlik işçi ile 49272.2 \$ gelir ve SET III için 4 traktör ve 3 mevsimlik işçi ile 65552.1 \$ en yüksek gelirlerin elde edildig̉i alterntifler olarak bulunmuştur.

\section{Sistem seçimi}

Model çözümününVII. Aşamasında yeralan 42, 43 , 44 ve 45 nolu eşitlikler yardimi ile SET'ter arasında seçim yapmak olanaklıdır. Çizelge 10,11 ve 12 'deki makina sabit maliyetlerinin dahil edildiği sonuçlardan en büyük gelire sahip olan alternatiflere ilişkin olarak $L T, P L, \sigma$ ve PT parametreleri hesap-lanarak sistem seçim aşamasına başlanmıștır. Bu parametrelere ait sonuçlar Çizelge $13^{\prime}$ de verilmiştir.

Çizelge 13'deki en uygun sistem seçimi en büyök PT, PL değerine ve en küçük o değerine bakilarak belirlenir. Çizelge 13 incelendiğinde sistemin toplam iş gücô gereksiniminin (LT) SET l'den SET IIl'e doğru azaldığı, insan iş gücü birimine düșen net gelirin (PL) ise arttığı görülür. Gereksinim duyulan işgücünün-standart sapması đ'nın azaldığı görülür.

Mekanizasyon maliyetlerinin dikkate alınarak seçim yapılması durumunda SET III D, ve SET III E seçenekleri arasından seçim yapmak gerektiği görülür Işletme gelirinin yüksek olmast hedefi goz önünde bulunduruldug̈unda SET III E sisteminin tercih edilebileceg̉i ortaya çıkar.

Çizelge 10. SET I için elde edilen model çŏzüm sonuçlati.

\begin{tabular}{|c|c|c|c|c|c|c|c|c|c|c|}
\hline \multirow{2}{*}{\multicolumn{2}{|c|}{ Bulgular }} & A & \multicolumn{2}{|c|}{ B } & \multicolumn{2}{|c|}{ C } & \multicolumn{2}{|c|}{ D } & \multicolumn{2}{|c|}{$E$} \\
\hline & & & 1 & 2 & 1 & 2 & 1 & 2 & 1 & 2 \\
\hline Buğday & ha & 154.33 & 111.68 & 138.505 & 111.68 & 154.26 & 111.68 & 138.505 & 111.68 & 154.26 \\
\hline Pamuk & ha & 1.266 & 0.97 & 1.75 & 0,97 & 2.33 & 0.97 & 1.75 & 0.97 & 2.33 \\
\hline Misır I & ha & 0 & 2.75 & 0 & 2.75 & 0 & 2.75 & 0 & 2,75 & 0 \\
\hline Misir II & ha & 2.63 & 0 & 1.801 & 0 & 2.97 & 0 & 1.801 & 0 & 297 \\
\hline Traktör/C & ir (adet) & 5,56 & 5 & 5 & 6 & 6 & 5 & 5 & 6 & 6 \\
\hline Mevsimli & adel) & 2.76 & 2 & 3 & 2 & 3 & 2 & 3 & 2 & 3 \\
\hline Gelir \$ & & 61415.7 & 34882.78 & 54797.8 & 24211.77 & 56689.2 & 29508.13 & 48211.5 & 18837.13 & 493265 \\
\hline
\end{tabular}

A Makine sabit maliyeti hariç traktörün karar değişkeni alındığı alternatif B1-B2-C1-C2 : Makine sabit maliyeti hariç ve traktörün model girdisi alındığı alternatif D1-D2-E1-E2 Makine sabit maliyeti dahil ve traktörün model girdisi alındiği alternatif

Çizelge 11. SET II için elde edilen model çözüm sonuçları.

\begin{tabular}{|c|c|c|c|c|c|c|c|c|c|c|}
\hline \multirow{2}{*}{\multicolumn{2}{|c|}{ Buigular }} & \multirow[t]{2}{*}{ A } & \multicolumn{2}{|c|}{ B } & \multicolumn{2}{|c|}{ C } & \multicolumn{2}{|c|}{$D$} & \multicolumn{2}{|c|}{$E$} \\
\hline & & & 1 & 2 & 1 & 2 & 1 & 2 & 1 & 2 \\
\hline Buğday & (ha) & 154.37 & 111.68 & 130.32 & 11168 & 154,26 & 111.68 & 130.32 & 111.68 & 154.26 \\
\hline Pamuk & (ha) & 1.227 & 0.97 & 1.33 & 0.97 & 1.33 & 0.97 & 1.33 & 0.97 & 1.33 \\
\hline Misır I & (ha) & 0 & 2.75 & 0 & 2.75 & 0 & 2.75 & 0 & 2.75 & 0 \\
\hline Misir II & (ha) & 274 & 0 & 2.97 & 0 & 2.97 & 0 & 2.97 & 0 & 2.97 \\
\hline Trak./Op & (adet) & 4.728 & 4 & 4 & 5 & 5 & 4 & 4 & 5 & 5 \\
\hline Mevsimi & adet) & 2.76 & 2 & 3 & 2 & 3 & 2 & 3 & 2 & 3 \\
\hline Gelir \$ & & 61180 & 37767.91 & 51303.7 & 25220.9 & 57601 & 31691,73 & 44258.72 & 19144.73 & 49272.2 \\
\hline
\end{tabular}


Çizeige 12 SET III için elde edilen model çōzüm sonuçları.

\begin{tabular}{|c|c|c|c|c|c|c|c|c|c|c|}
\hline \multirow{2}{*}{\multicolumn{2}{|c|}{ Bulgular }} & \multirow[t]{2}{*}{ A } & \multicolumn{2}{|c|}{ B } & \multicolumn{2}{|c|}{ C } & \multicolumn{2}{|c|}{$\bar{D}$} & \multicolumn{2}{|c|}{$E$} \\
\hline & & & 1 & 2 & 1 & 2 & 1 & 2 & 1 & 2 \\
\hline Buḡday & (ha) & 154.37 & 111.68 & 116.29 & 111.68 & 154.26 & 111.68 & 116.29 & 111.68 & 154.26 \\
\hline Pamuk & (ha) & 1.227 & 0.97 & 1.33 & 0.97 & 1.33 & 0.97 & 1.33 & 0.97 & 1.33 \\
\hline Misir I & (ha) & 0 & 2.75 & 0 & 2.75 & 0 & 2.75 & 0 & 2.75 & 0 \\
\hline Misir II & (ha) & 2.74 & 0 & 2.97 & 0 & 2.97 & 0 & 2.97 & 0 & 2.97 \\
\hline Traktör/C & r (adet) & 3.97 & 3 & 3 & 4 & 4 & 3 & 3 & 4 & 4 \\
\hline Mevsimli & adet) & 2.76 & 2 & 3 & 2 & 3 & 2 & 3 & 2 & 3 \\
\hline Gelir \$ & & 74022 & 52826.02 & 55337.1 & 40781,02 & 73508 & 47017.77 & 49273.91 & 34972.77 & 655521 \\
\hline
\end{tabular}

Çizelge 13. Madele ilişskin sistem seçim kriterleri.

\begin{tabular}{|l|l|l|l|l|l|}
\hline \multicolumn{5}{r|}{ SETler } & \multicolumn{5}{|l|}{ Sistem seçim ölçütleri } \\
\cline { 2 - 6 } \multicolumn{2}{c|}{} & LT & PT & \multicolumn{1}{l|}{ PL } & \multicolumn{1}{l|}{} \\
\hline SET I B & 4393.97 & 29508.13 & 6.71 & 336.77 \\
\hline SET II B & 3986.78 & 31691.73 & 7.94 & 273.53 \\
\hline SET III B & 3596.09 & 47017.77 & 13.07 & 224.471 \\
\hline SET I C & 5662.39 & 48211.5 & 8.51 & 439.75 \\
\hline SET II C & 4998.33 & 44258.72 & 8.85 & 348.59 \\
\hline SET III C & 4416.03 & 49273.91 & 11.15 & 252.167 \\
\hline SET I D & 4393.97 & 18837.13 & 4.28 & 336.77 \\
\hline SET II D & 3986.78 & 19144.73 & 4.80 & 273.53 \\
\hline SET III D & 3596.09 & 34972.77 & 9.72 & 224.471 \\
\hline SET I E & 6148.78 & 49326.5 & 8.022 & 463.61 \\
\hline SET II E & 5591.08 & 49272.2 & 8.81 & 378.954 \\
\hline SET III E & 5055.27 & 65552.1 & 12.96 & 315.171 \\
\hline
\end{tabular}

\section{Sonuç}

Adnan Menderes Üniversitesi Ziraat Fakültesi Araştırma ve Üretim Çiftliği verileri dikkate alınarak gerçekleştirilen bu model çalışması 3 farklı alet-makina seti için planianmış-tır.Oluşturulan modelde mevsimlik işçi ve traktör sayısı amaç fonksiyonunda karar değișken olarak alınmıştır. Çözüm ile bulunan bu değişkenler daha sonra model girdisi olarak kullanılmıștır.

Mevsimlik işçi kriterlerinin dikkate alınması dưrumu ile model çalışmasına gerçekçi bir yaklaşım sağlanmaya çalışıımıştır. Ancak sonuçların güvenirliliği kullanılan verilerin doğruluğu ile orantılıdır.

Modelden elde edilen sonuçlar incelendiğinde, büyük güçlö traktörün yer aldığı alet-makina setinin işletme için optimum sonuçiarı verdiği söylenebilit. SET III D seçeneğinde elde edilen bu sonuçlara lisşkin ayrıntılar Çizelge $14^{\prime}$ de verilmiş̧ir. Işletmede büyük güçlư traktör ile büyük kapasiteli ekipmanların kullaniımasi gerektiḡi sonucuna ulaşılmaktadır. Sonuç olarak bulunan ürün deseninde I. ürün mısıra yer verilmemekte pamuk ile II. ûrûn misira ise ihmal edilebilecek kadar az yer verilmektedir. Üretimin tamamen buğdaya yönelmiş olması işletmedeki işçi maliyetlerinin yüksek olmasından kaynaklanmaktadır. Tek ürüne yönelmedeki faktörlerden birisi de üretimde girdi olarak kullanılan materyallerinin (örneğin gübre) fazla kullanılmasıdır.

Pamuk ve mısır için küçuak alanlar ön görüldüguünden bunlar ihmal edilerek, işletmede 155.6 ha alanda buğday yetiştirilmesi düșünülebilir. Bu koşulda, ekipmanlar için 10 ve traktörler için 15 yillık amortisman süreleri varsayımı ile işletme de bulundurulması gereken ekipman sayıları ve teknik özellikleri Çizelge $15^{\prime}$ deki gibi olur.

Çizelge 14 Optimum seçenek bilgileri (SET III D için).

\begin{tabular}{|l|c|}
\hline Parametreler & Bulgular \\
\hline Traktör sayısı (adet) & 4 \\
\hline Traktör gücü (kW) & 58,8 \\
\hline Operatör sayısı (adet) & 4 \\
\hline Mevsimlik ișçi sayısı (adet) & 3 \\
\hline Buğday (ha) & 154,26 \\
\hline Pamuk (ha) & 1,33 \\
\hline Mısır II (ha) & 2,97 \\
\hline Gelir (\$) & 65552,1 \\
\hline
\end{tabular}

Çizelge 15. Işletmede bulundurulmasi gereken ekipman sayıları ve teknik ozellikleri.

\begin{tabular}{|l|l|l|}
\hline Ekipman & Ozellĭ̆i & Sayisi \\
\hline Diskli tımmık & 28 sıralı asilır $254 \mathrm{~cm}$ iş genişlik & 3 adet \\
\hline Kom.tahıl ekim mak. & 22 ayakli $264 \mathrm{~cm}$ iş genişlikli & 3 adet \\
\hline Kuiaklı pulluk & 4 gövdeli $120 \mathrm{~cm}$ iş genişlikli & 3 adet \\
\hline Sant.güb. dağg. Mak. & Çift diskli $2000 \mathrm{~cm}$ iş genişlikli & 1 adet \\
\hline SettemMakinası & 8 kovalı $1000 \mathrm{~cm}$ iş genişlikli & 1 adet \\
\hline Tarım arabası & 6 tonluk & 2 adet \\
\hline Tarla Pulverizatörü & 800 it $900 \mathrm{~cm}$ iş genişlikli & 1 adet \\
\hline Tesviye küreği & $2 \mathrm{~m}$ iş genişlikli & 2 adet \\
\hline Traktör & 80 BG'lük & 4 adet \\
\hline
\end{tabular}




\section{Kaynaklar}

Anonim, 1994. T.C. Tarım ve Köyişleri Bakanlığı Tarımsal Araştırmalar Genel Múdürlúğú Akdeniz Tarımsal Araştırma Enstitüsü Müdūrlüğa Araştırma Raporları, Antalya.

Anonim, 1998a. T.C. Tarım ve Köyișleri Bakanlığı Tarımsal Araştırmalar Genel Müdurluğá Nazilli Pamuk Araștima Enstitüsü Müdürlüğü Araştirma Raporlani, Aydin.

Anonim, 1998b. Türkiye Tarim Kredi Kooperatifleri Merkez Birliği Gen. Müd. Fiyat Sirküleri, No:288, Ankara.

Audsley, E.1979. Planning an Arable Farm's Machinery Needs- a Linear Programming Application. The Agricultural Engineer $v(34), n-1$.

Audsley, E.1983. Labour and Machinery Planning Program. National Institute of Agricultural Engineering, Silsoe,

Coşkun, B., Özarsian, C, ve Baş, S. 1999. ADÜ Ziraat Fakültesi Çiftliği Için Optimal Bitkisel Uretim Deseninin LP Tekniği lle Belirlenmsi. ADU Araștırma Fonu, Bitirme Raporu, Proje No:ZRF-96016, Aydın.

\section{EK 1: SEMBOLLER}

A : Toplam üretim alani (ha)

A : iürünü için üretim ala ขl (ha)

A $\quad$ i ürünü için makinanir yıllik kullanım alanı (ha/yıl)

$\mathrm{BC}_{i} \quad$ i ürûna için değişken ş'derler (\$/ha)

$\mathrm{C}_{n} \quad$ : Ișçi ücreti $(\$ / h)$

CGG Çekigücü $(\mathrm{kW})$

D Taşima mesafesi $(\mathrm{km})$

$D_{i} \quad$ :Periyotlardaki çalişilabilı süreler (h)

e Etkinlik

EKMG : Eșdeğer kuyruk mili gücù (kW)

$\mathrm{F} \quad$ :Yakıt birim fiyatı (\$/t)

FC, : i ürünú için ha başına mak na sabit maliyeti ( $\$ / h a)$

FC) : i ürünü için yıllık makina sabit maliyeti (\$/yıl)

$\mathrm{F}_{0} \quad$ : Gübre fiyatı $(\$ / \mathrm{kg})$

$F_{s} \quad$ : llaç fiyatı $(\$ / k g)$

$\mathrm{F}_{\text {su }} \quad$ Sulama maliyeti (\$/ha)

$\mathrm{F}_{\mathrm{t}} \quad$ : Tohum fiyatı $(\mathrm{S} / \mathrm{kg})$

$F_{Y} \quad$ : Yağın birim fiyatı (\$/t)

g : Işlem sayısı (adet)

i : Üretimi yapılacak ürün çeşidi sayısı (adet)

j : Oretimin gerçekleștirildiği periyıst sayısı (adet)

$K_{1} \quad:$ Traktör sayısı (adet)

$\mathrm{K}_{2} \quad$ : Mevsimlik işçi sayısı (adet)

LT : Sistemin toplam işgüü gereksin imi (h)

$\mathrm{Mgü}_{i} \quad$ : i ürüna için gübre gideri (\$/ha)

Mili, : i ürünü için ilaç gideri (\$/ha)

Miş̧ : : i ürünü için operatör gideri (\$/ha)

MKMG : Maksimum kuyruk mili gúcú (kW)

$\mathrm{Mm}_{\mathbf{1}} \quad$ : i ürünû için mevsimlik ișçi gideri (\$/ha)

$\mathrm{Msu}_{\mathrm{i}} \quad \mathrm{i}$ arünu için sulama gideri (\$/ha)

Mtoh $_{\mathrm{i}} \quad$ : iürünü için tohum gideri (\$/ha)

Myağ, : i ürünü için yağ gideri (\$/ha)

Myak, ; i ürünủ için yakıt gideri (\$/ha)

Myük i ûrünü için yưklenici gideri (\$/ha)

Evcim, H. U.1986. Tarımsal Ișletmelerde Doğrusal Programlama Yardımıyla Mekanizasyon ve Işçilik Planlaması E.U.A.Araştırma Fonu, Araştırma Raporu Prj. No 112, Izmir.

Evcim, H. U.1990. Tarımsal Mekanizasyon Işletmeciliği ve Planlaması VeriTabanı. E.U.Ziraat Fakültesi Yayınları no:495, lzmir.

Özbaydur, H. A.,1996. Söke Yöresinde Bazı Örnek İşletmelerde Karşilaştırmali Mekanizasyon Planlaması Uygulamaları.YL. Tezi.E.U. Fen Bilimleri Enstitúsü. Tarım Makinaları $A B D$, Izmir.

Sakai, M. Kurata K. ve Ichikawa J. 1978. Simulation On "labourMachinery-Crop" System in Newly Developed fięld CIBR Symposium Congress Papers of the 5 . Section Ermatingen, Schweiz.

N

$P_{i}$

PT

q

$q_{i k}$

$q_{n}$

Q

$q_{n}$

$q_{i}$

$\mathrm{T}$ ii
$\mathrm{T}$

TCi

TCi

$T_{0}$

$T_{\text {II }}$

TR

$T_{1}$

$\mathrm{U}+\mathrm{L}$

UP,

$\checkmark$

w

X

Y

Yağ

Yak

$Y_{i}$

$\mathrm{ZC}_{i}$
$\sigma$
: Motor gúcú (kW)

: Sulama sayısı (adet)

; ürüü için net gelir (\$/ha)

: i ûrünü için mekanizasyon maliyeti hariç(sabit maliyetier)

net gelir (\$/ha)

Sistemin toplam net geliri (\$)

Genel alet-makina zaman gereksinimi ( $h / h a)$

i ürünü ve k ekipmanı için zarnan gereksinimi (h/ha)

:i işlemi için toplam makina zamani gereksinimi (h/ha)

Her periyotta çalışılabilir süre olarak alet-makine gereksinimi (h/ha)

j.periyotta i ürünü için gerekli alan iş̧ başarısı (h/ha)

Taşıma işlemi için zaman gereksinimi (h/ha)

Her periyotta çalışılabilir süre olarak işgücü gereksinimi

(h/ha)

j. periyotta i ürün için iş̧ücũ gereksinimi ( $h / h a)$

Toplam hasat alanı (ha)

Tarim arabası kapasitesi $(\mathrm{kg})$

: i úrünü için giderler topiamı (\$/ha)

: Kullanilan gübre miktarı ( $\mathrm{kg} / \mathrm{ha}$ )

: i ürünü için makinanın yıllık kullanım süresi (h/ha)

Kullanılan ilaç miktarı $(\mathrm{kg} / \mathrm{ha})$

: i urününden elde edilen gelir (\$/ha)

Kullanilan tohum miktarı ( $\mathrm{kg} / \mathrm{ha}$ )

: Yukleme boşaltma zamani (1.2 h/ha)

i ürününün fiyatı $(\$ / \mathrm{kg})$

llerleme hizi $(\mathrm{km} / \mathrm{h})$

Iş genişliği (m)

Yuklenme oranı

Yakıt etkinliği (IUh.kW)

Yağ tüketimi ( $(1 / \mathrm{h} / \mathrm{h})$

Yakıt tüketimi (It/h)

i ürününün verimi $(\mathrm{kg} / \mathrm{ha})$

i ürünü için diğer giderler (\$/ha)

Isgücü gereksiniminin standart sapması 


\section{EK LP denklem örneği}

Set I Mevsimlik Işçi Dahil

Amaç Fonk Pi için Cmax $=743,47$ X1+981,521 X2+530,575 X3+410,46 X4-10671+X5-1290 X6

Kısıtlar: Alan

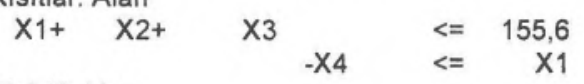

\begin{tabular}{|c|c|c|c|c|c|c|c|c|c|c|c|}
\hline \multicolumn{11}{|c|}{ Alet-Makina } & \\
\hline 3,925 & ${ }^{X 1}$ & 0 & ${ }^{X}{ }_{+}$ & 0 & ${ }^{x 3}+$ & 0 & X4- & 291,09 & X5 & $<=$ & 0 \\
\hline 0,832 & ${ }^{X 1}$ & 11,596 & ${ }_{+}^{X 2}$ & 12,91 & ${ }_{+}{ }^{x}$ & 0 & $\times 4-$ & 111,68 & $\times 5$ & $<=$ & 0 \\
\hline 0 & ${ }^{X 1}$ & 3,128 & ${ }_{+}^{X 2}$ & 1,814 & ${ }^{\times 3}$ & 0 & X4- & 220,13 & $\times 5$ & $<=$ & 0 \\
\hline 5,5 & ${ }^{X 1}$ & 2,695 & ${ }_{+}^{X}$ & 2,176 & ${ }^{x 3}$ & 19,122 & X4- & 162,07 & $\times 5$ & $<=$ & 0 \\
\hline 0 & ${ }^{x 1}$ & 0,832 & $\mathrm{X}_{+}$ & 1,058 & ${ }^{x 3}$ & 6,12 & $\times 4-$ & 208,55 & $\times 5$ & $<=$ & 0 \\
\hline 0 & ${ }^{X 1}$ & 0 & ${ }^{X} 2$ & 0 & ${ }^{\times 3}$ & 0,293 & X4- & 216,1 & $\times 5$ & $<=$ & 0 \\
\hline 0 & ${ }^{X 1}+$ & 1,55 & ${ }_{+}^{X 2}$ & 0 & $\begin{array}{r}x^{2} \\
+\end{array}$ & 0 & $\times 4-$ & 256,85 & $\mathrm{X} 5$ & $<=$ & 0 \\
\hline 11,449 & $\mathrm{X} 1$ & 4,002 & $\times 2$ & 11,457 & $\mathrm{x} 3$ & 3,15 & X4- & 319,69 & $\times 5$ & $<=$ & 0 \\
\hline
\end{tabular}

Işçi
$0 \times 1+0 \times 2+$
$0 \times 3$
$0 \times 4-291,09 \times 6<=0$
$2 \times 1+0 \times 2+$
$0 \times 3$
$0 \times 4-111,68 \times 6<=0$
$0 \times 1+376, \quad \times 2+27,2 \times 3$
$0 \times 4-220,13 \times 6<=0$
$0 \times 1+\quad 0 \quad x_{2+}$
$0 \times 3^{+}$
$0 \times 4-162,07 \times 6<=0$
$0 \times 1+69,8 \times 2+127 \times 3{ }^{+} \quad 179 \times 4-208,55 \times 6<=0$
$0 \times 1+29,2 \times 2+127 \times 33^{+} \quad 104 \times 4-216,1 \quad \times 6<=0$
$0 \times 1+320, \quad X 2+$

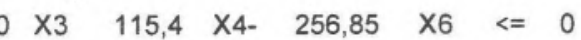
$0 \times 1+100 \times 2+$
$0 \times 3$
$0 \times 4-319,69 \times 6<=0$ 